\section{Timelines Engaging with Critical Thinking through Visual Contextualization}

Alice Vialard

Northumbria University

\section{Peter Holgate}

Northumbria University

\author{
Shaun Young \\ Northumbria University
}

\section{ABSTRACT}

In architectural education, the use of precedents to inform studio design process is recognized, supported and mandated by many professional architectural accreditation boards. However, the study of precedents in taught history and theory courses may not automatically lead to application in architectural design. Too often, the relationship remains superficial, and primarily visual or formal. The rise of online sources means that websites have become a major source for students' collections of architectural precedents. Platforms, such as Pinterest, provide a repository of alluring images, allowing access to a burgeoning array of precedents. Such ease of access may however reinforce superficial readings of buildings through images that mitigate against deep analysis. Architectural educators seek to teach students to interrogate examples beyond the immediate image, and to instill critical thinking in order that precedent analysis becomes meaningful when making informed decisions during the design phase.

This innovative proposal builds upon architecture's visual bias by introducing evaluative analysis in the form of a pictorial timeline that seeks to contextualize a specific building within a larger set of precedents as the starting point for a critical framework. This provides students with a tool for critically organising visual knowledge in order to create new design applications. This timeline assignment, which has developed over 4 years, has evolved from a method to select and organize precedents into a comparison tool that can practically shape and define architectural strategies. When this knowledge is transferred to studio design projects, such architectural strategies enable deep evaluation of buildings towards facilitating justified design decisions.

Employing critical thinking to assess architectural precedents in terms of relevance and transferability thereby aligns the teaching of history and theory to application in the design process within architectural studios.

\section{CRITICISM IN ARCHITECTURAL STUDY}

At a time where knowledge has become extensively available via online sources, it is essential for students to develop skills of critical thinking in order to judge the quality of information that they encounter. While the teaching of critical thinking skills may often focus upon 'declarative' knowledge acquisition (identifying and selecting data), vocational disciplines such as architecture should also develop evaluative judgment with respect to knowing what to do with this knowledge. This practical aim is discussed herein with respect to the teaching of architectural history, theory and criticism, in considering how students can build and develop critical frameworks that enable them to engage with historical and contemporary architecture constructively. Having developed such a personal critical framework, students will then be able to reflect on the systematic application of history and theory to their own design work, as well as to the considered critique of the work of others.

Fundamental to learning and practice, students of architecture are encouraged to think and communicate through visual and graphical approaches. The delivery of relevant content in lectures naturally tends towards visual images - photographs, diagrams, 
drawings, technical details etc. Building upon architectural education's professional employment of image-based practice, this initiative has sought to incorporate disciplinary-relevant visual methods towards the formation of this particular critical framework, nameIy the illustrated timeline. In this format, the timeline assignment is not used as a declarative illustration of independent facts, but is more actively engaged as a visual methodology to analyse and compare precedents ${ }^{1}$. Thereby it builds new, appreciative and applicative knowledge, as well as communicating key concepts and ideas. The timeline provides a lens that 're-frames' the research question in anticipation of the writing of a critical essay about a building that students have selected themselves, according to personal preferences and project relevance. Instead of writing the essay twice (i.e. a first draft and a final version) the first draft is replaced by three components; a diagrammatic analysis of the chosen building; a timeline that seeks to synthesize multiple perspectives and lines of inquiries; and finally an abstract that seeks to develop a critical research question worthy of deeper inquiry and exploration.

\section{HISTORY, THEORY AND PRECEDENT ANALYSIS}

The teaching of architectural history and theory forms a key pillar in the professional accreditation of most schools of architecture education in Europe and North America. According to the European directive, the training of an architect should include an 'adequate knowledge of histories and theory'2. The practical application of principles derived from History and Theory teaching to design studio projects has been particularly encouraged through the study and analysis of precedents. For example, the National Architectural
Accrediting Board (NAAB) for schools of architecture in the USA sets a key criterion in 'Realm A: Critical Thinking and Representation' in its 'Conditions for Accreditation' document. Criterion A.6, 'Use of Precedents' prescribes the 'ability to examine and comprehend the fundamental principles present in relevant precedents and to make informed choices about the incorporation of such principles into architecture and urban design projects ${ }^{3}$. In the United Kingdom, General Criteria 7 of the joint Architects Registration Board (ARB) / Royal Institute of British Architects (RIBA) requires that the architecture student demonstrates an understanding of 'the need to critically review precedents relevant to the function, organization and technological strategy of design proposals'4.

These policies recognize that engagement with architectural history and precedents forms a legitimate part of the creative act, aligning to constructivist educational principles 5 . As a fundamental method of learning, analogical thinking creates new knowledge by establishing systematic correspondences between two analogs, enabling the qualitative and / or quantitative assessment of their similarities and differences ${ }^{6}$. By means of comparative inferences, such thinking may lead to new models. Hence, the analysis of precedents can be seen to function as an application of analogical thinking towards the production of new knowledge and creative opportunities ${ }^{7}$. As a central part of the design process, precedents may become systematic keys to help students unlock and develop informed design decisions ${ }^{8}$. For example, Leach considers six metrics towards the categorization of knowledge in architectural history: style and period; biography; geography and culture; type; technique; and theme $\&$ analogy 9 . These metrics provide entry points into the analysis of past architectural projects,

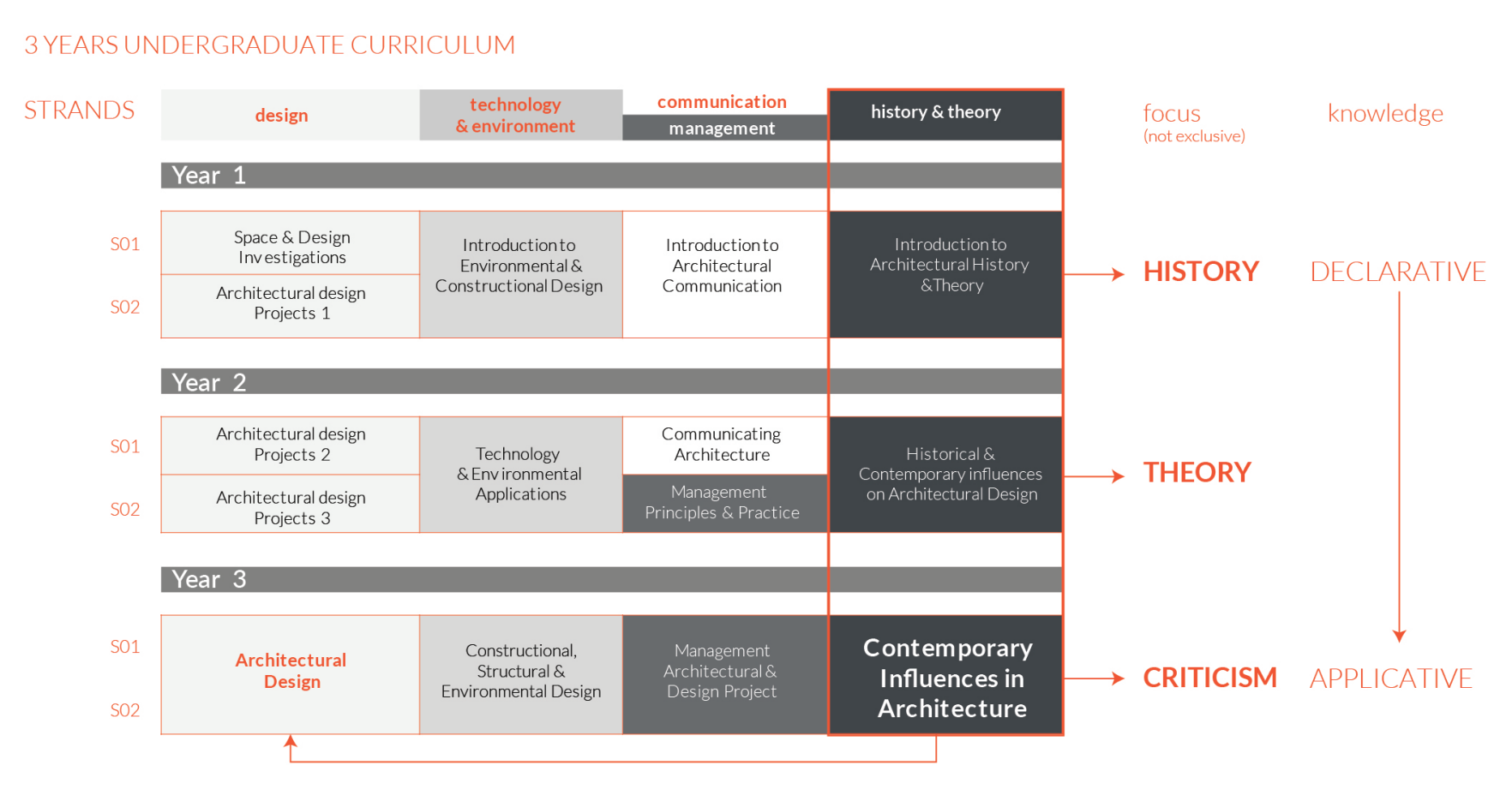

Figure 1. The place of history and theory in undergraduate bachelor program at Northumbria University, highlighting the intended focus for each level. 
however, they may be similarly relevant to the critical assessment of contemporary buildings, as well as establishing benchmarks for design aspirations for speculative projects, through the establishment of project-specific comparative frameworks.

The courses of architecture and interior architecture at Northumbria University are predicated upon theories of constructive alignment, whereby content delivery, learning outcomes and assessment methods seek to entrap the student in a 'web of consistency'10. This strategy extends to program level, wherein (for exampleconstructional, technological and environmental principles, as communicated through lectures, apply practically to studio design projects. In contrast, teaching of history and theory is broader, more divergent and necessarily discursive at the outset of the course, having to bring the student up to speed with a rich and complex field in its own right. Consequently, first year taught content provides an overview of architectural history, focusing upon the acquisition of general, declarative knowledge; style and periods, movements, technological developments and key case studies of architects and buildings. The second year introduces more theorization, commencing relevant alignments with studio design applications ${ }^{11}$. The role of the third year, in anticipation of award-year graduate attributes, seeks to develop criticality, evaluative judgement, and systematically-argued application (Figure1).

\section{STRUCTURE OF THE ASSIGNMENT - METHODOLOGY}

The teaching of the award-year course "Contemporary Influences on Architecture" seeks to expose students to current theories and approaches to architecture employed in contemporary practice. In order to engage with contemporary architectural theories, students are asked to select a building that has influenced their way of thinking about architecture (preferably built post 1984 and to write a criti-cal essay about it. Coursework splits into formative and summative assessment exercises, with the formative elements employing visual methods to construct the student's theoretical framework. The first semester (formative emphasizes pictorial communications, while the second semester (summative) focuses upon academic and critical writing (Figure 2). The formative assessment provides an alternative to text by 're-framing' traditional research within this visual framework. This coursework is split into three discrete components:

1. A 'building analysis' of their selected precedent forces the student to critique, to redraw, and to analytically diagram the specific qualities of their case study. The focus of this analysis must be supported by a reasoned argument explaining how this building contributes to contemporary discourses of architecture.

2. The 'illustrated timeline' maps several lines of inquiries, such as cultural, political and contextual influences. It synthesises traditional data collection (historical, theoretical, precedent studies into a single visual framework, enabling new knowledge to be constructed;

3. The 'critical abstract' articulates the student's intentions through academic writing. It formulates a research question, based upon the data analysis of the two first components, and outlines the structure of the forthcoming essay.

The summative assignment synthesizes these inquiries into an illustrated critical essay regarding their self-selected building, developing

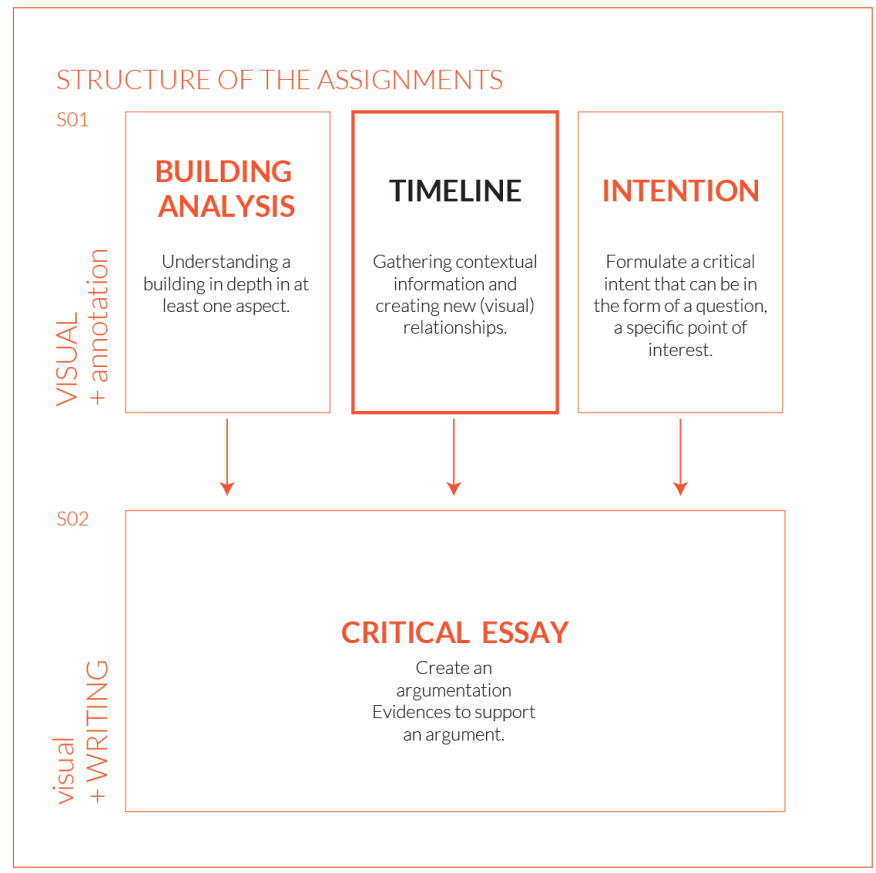

Figure 2. Structure of the assignment - different emphasis on visual elements by semester ( $\mathrm{SO} 1$ and $\mathrm{SO} 2$ ) and by type of assignment showing how the timeline contributes to the making of the written essay.

an argument as well as a methodology to support their hypotheses, derived from an evidenced base. By formulating their own self-chosen topic, learners develop higher levels of criticality, demand and engagement with the broader context of theory and history. Selfselection also encourages students to take ownership of their own disciplinary interests and potential career development.

When assessing architectural work, its contextual application can become the basis for justified critical thinking. Relevant examples of engagement with critical thinking in the arts derive from critics who evaluate the artefact through establishing different visual thinking strategies. Panofsky and Drechsel establish three levels of interpretations, including the intrinsic meaning of a work ${ }^{12}$, and Baxandall stresses the importance of the intention ${ }^{13}$. These approaches seek not only to understand the meaning of the artefact, but also to consider the wider context in which the artefact emerges (such as innovation in a technique for example).

A comparable approach applies with the evaluation of buildings. Students are guided to consider intentions, as well as interpretation, in order to contextualize the case study and to understand its meaning and relevance to the discourse of contemporary architecture. Furthermore, where their selected precedent relates to substantive themes and types of their studio project, this 'double duty' may facilitate the focus of the study. For example, inquiries may be based on shared building types, use of a specific material, specific site conditions, spatial and lighting concepts, environmentally sustainable approaches, or other associated themes. In such cases, the assignment clearly integrates history and theory to studio work, making it more relevant by integrating visual thinking and communications. 
Following this building analysis, the students gather relevant contextual information, in which precedents play an essential role. Precedents can provide alternative approaches to the selected theme(s). Where the building analysis encourages students to evaluate the precedent in terms of primary architectural themes (e.g. massing, proportion, elements etc.), the second stage seeks to transpose notions of iconography into iconology, by integrating the context in which the building emerges. This timeline exercise seeks to provide a means to map and organise this gathered information and precedents.

\section{TIMELINE AS SYNOPTIC - TOOL}

Timelines are employed in historical studies, chiefly to organize events, their sequence and their interrelated significance with the overarching historical context. Timelines can also be utilised to display visually quantitative information ${ }^{14}$. They are often linked to cartography, and can produce very elaborate graphical infograms that can illustrate narratives or simple chronologies ${ }^{15}$. Chronology arranges events in order of occurrence, highlighting the non-linearity of some processes. Timelines in architecture tend to record the evolution of architectural movements and their key figures ${ }^{16}$; wider influences can include historical events and technological developments providing a more global contextualisation ${ }^{17}$. As such, timelines become a relevant tool to understand the production of architecture by providing a contextual framework and a synoptic vision.

A rich timeline can incorporate various levels of complexity, thereby reflecting the designer's synthetic design methodology. Complexity may increase through richness of contextual information or through the depth of the student's analysis. The process of mapping may require categorization of the information into broader themes, including the multiple lines of inquiry that may build complexity, yet facilitate the contextualization of the building into more manageable parts. Such lines of inquiry may follow Leach's criteria', for example, including the evolution of a type, an architectural style in general, or (within the work of the architect) a specific technology, site, locale, or cultural context. Once these lines of inquiries are established, they provide the basis for selecting relevant precedents. The timeline becomes a visual comparative framework that situates the selected building within a wider context, as well as a tool for organizing and interpreting knowledge, providing students with synoptic views of knowledge capable of application in other contexts ${ }^{18}$.

\section{FROM TIMELINES TO DESIGN - STUDENT WORK}

Following its introduction, this assessment methodology has evolved progressively over the last four years. Initially conceived as a means to contextualize a building within a set of relevant precedents, the timeline exercise has developed into a comparative framework of architectural strategies and concepts, capable of influencing design processes in studio projects. The following examples consider multiple approaches towards precedent analysis, and illustrate divergent (yet applicable) interpretations of the assignment, highlighting the critical importance of selecting relevant and imaginative lines of inquiry that isolate the architectural strategies embedded within a set of precedents.

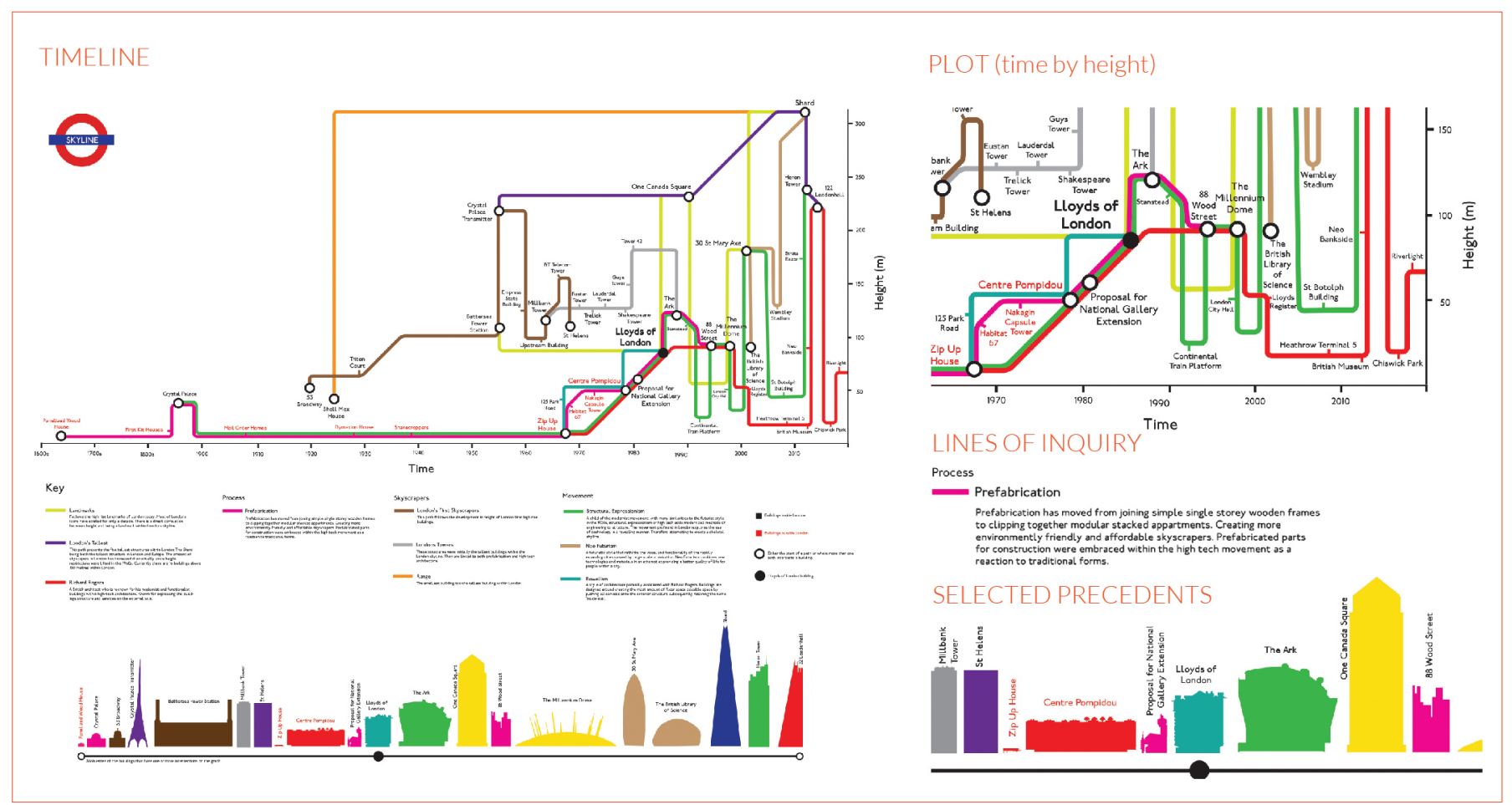

Figure 3. George Bradford-Smith's timeline for Lloyds of London - Academic Year 2015-16. 


\section{ORGANIZATION AND SELECTION OF PRECEDENTS}

Figure 3 presents a timeline that commences as chronological, organizing buildings by their year of completion ( $x$ axis), and their height ( $y$ axis). The pool of precedents materializes itself from different lines of inquiry that are relevant to the selected case study, namely the Lloyd's building of 1986. In this example, selected lines of inquiry include the works of Richard Rogers, city landmarks, London's tallest buildings, process (prefabrication), skyscrapers (functions, structures, locations) and architectural movements (structural expressionism, neo-futurism, Bowelism). These 'lines' are presented via individual colors as underground routes, accompanied with a short written summary as key to their categorisation. The graphic style and choice of font reflects Harry Beck's seminal design of 1933 for the London Underground tube map, itself an outstanding example of communicating a complex network in a visually communicative manner.

Where two or more of these lines cross, buildings located at the intersections are extracted, and plotted on the lower line as silhouettes. The lines produce contextual overlaps of all the precedents with the selected building, leading to deeper investigation. Consequently, a set of precedents that are relevant to conducting a critical appraisal of the case study emerges from this overlapping of lines, presenting a strong contextualization (both visual and analytical) of the building. This comparison enables an understanding of the role played by the Lloyd's building and structural expressionism in shaping London's skyline, identifying that many of the tallest buildings in the City emerge from this architectural movement.
Although lines of inquiries may be fairly broad, the intersections of such lines systematically identifies (and reduces) the pool of relevant precedents. Clearly, more focused and relevant criteria lead to a justified selection of precedents that facilitate analytical comparison, as well as design applicability where related to studio projects.

\section{ARCHITECTURAL STRATEGIES}

Where there is focused justification to select a specific building (perhaps being linked to a student's personal interest) the timeline may be employed as an analytical tool through the critical development of a visual comparative framework. For example, the study of de Rotterdam by OMA (Figure 4) looks at how the project is perceived, insofar as this building presents alternative conditions dependent upon from which side it is viewed; it can thus be perceived as a single building or as a set of discrete towers. By questioning the number of towers, this analysis considered the variety of architectural strate-gies that can be used to link sets of towers. Different methods of con-nections are highlighted, such as the incorporation of atria, elevated skywalks, and articulated servicing tower. Identification of such archi-tectural strategies enables a comparative study of towers through the presence of one or several of these strategies, suggesting the pos-sibility of developing new typologies and arrangements.

Figure 5 illustrates a study of the Chapel of Reconciliation by Reitermann and Sassenroth, a structure acting as both a memorial of a political situation (the division of Berlin), and the rebuilding of

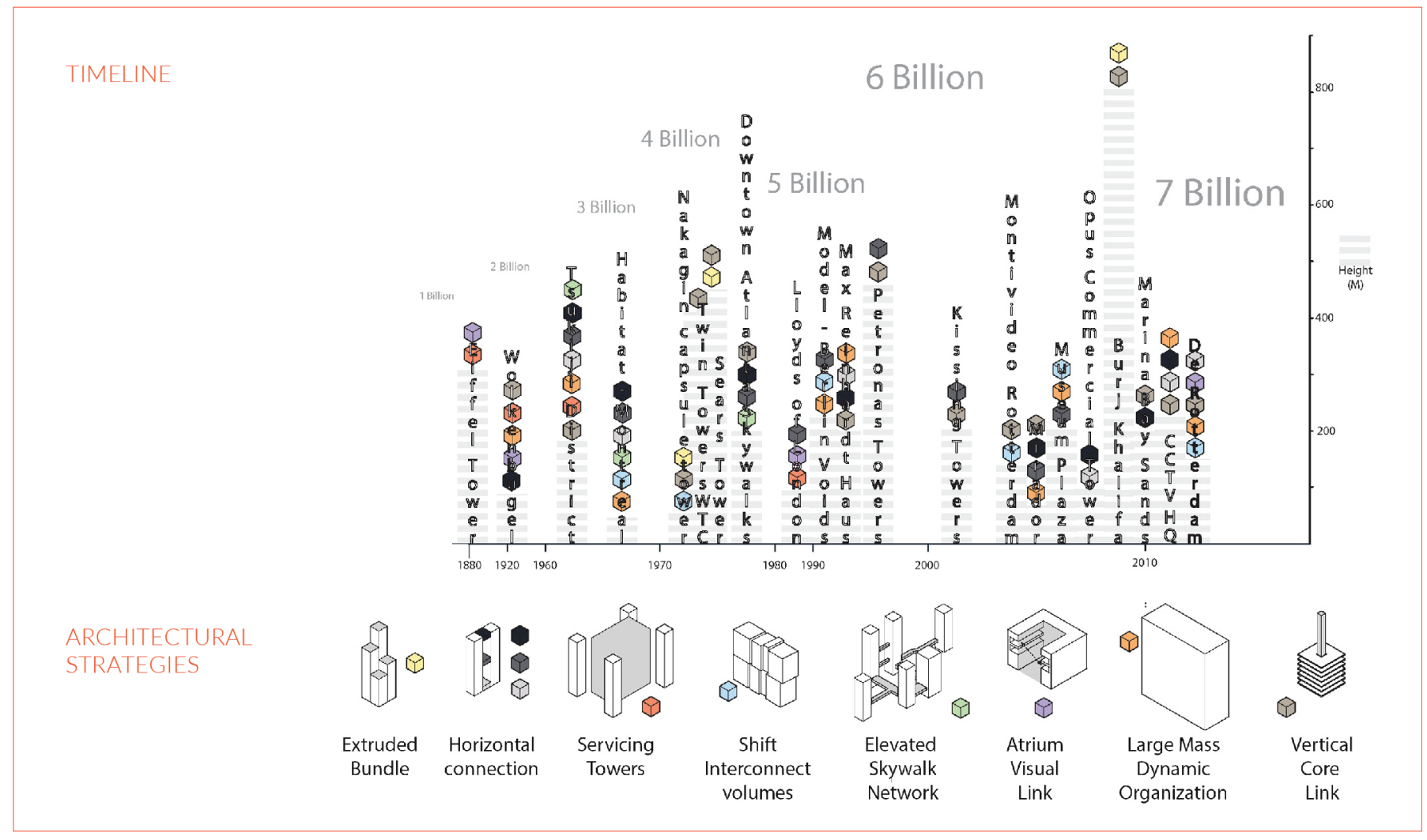

Figure 4. Shalin Mistry's timeline for De Rotterdam - Academic Year 2016-17. 


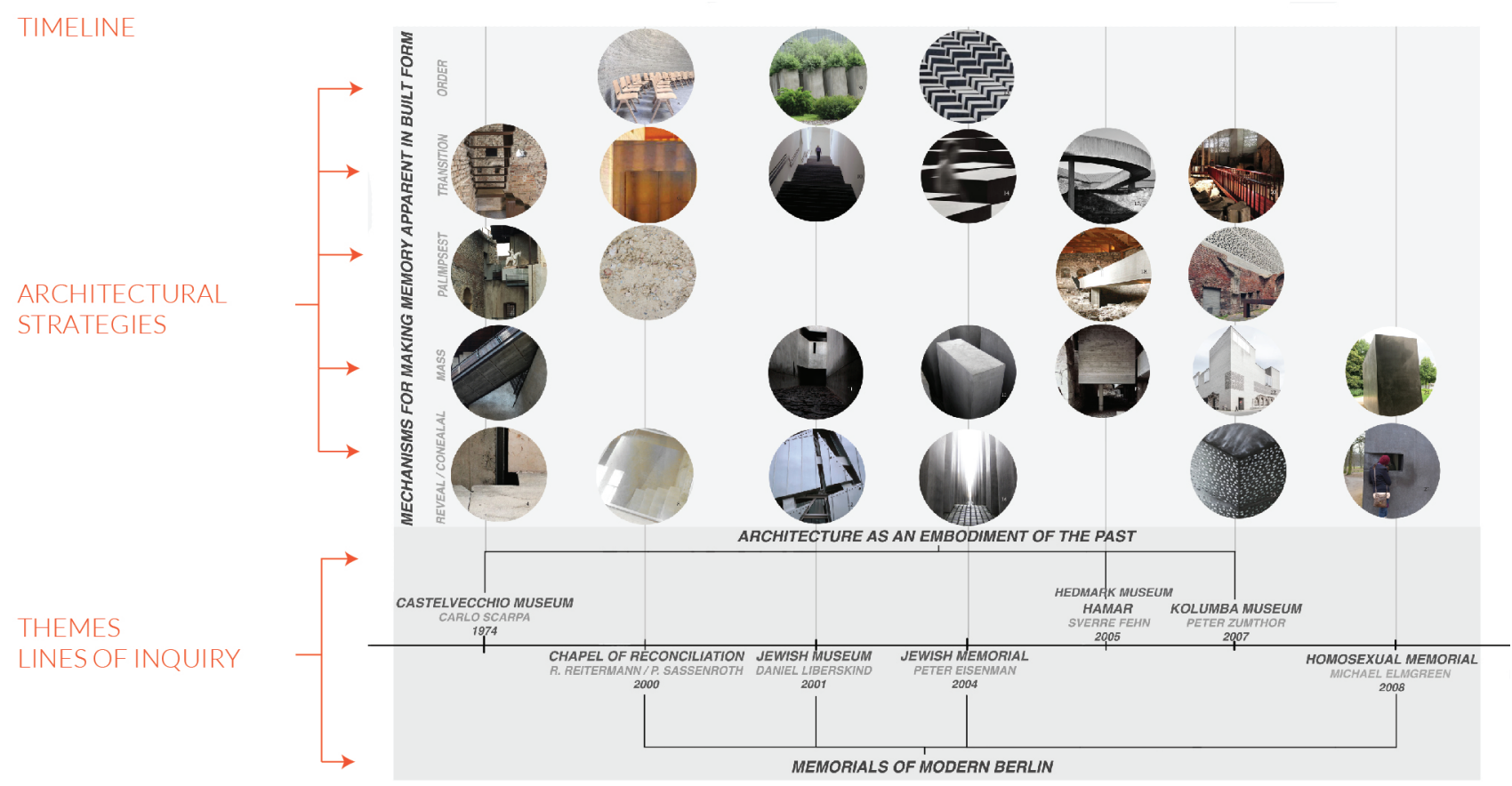

Figure 5. Connor Tulip's timeline for the Chapel of Reconciliation, Berlin - Academic Year 2017-18.

a chapel that had been partially destroyed. Hence, two key themes serve as significant lines of inquiry to select relevant precedents: the 'memorials of modern Berlin' that reflect the city's unique history, and the theme of creative reuse with 'architecture as an embodiment of the past'. Following selection of relevant precedents, the student isolates different mechanisms that relate the notion of memory to architectural strategies. These strategies, identified as 'reveal-conceal', 'mass', 'palimpsest', 'transition' and 'order', serve as a basis for effective comparison, with particular relevance to the analysis of the selected building. These identified strategies also emerge as first steps towards incorporation into the student's studio design project.

The student's ensuing critical essay, entitled 'The architecture of embodiment: the transmission of memory into built form', referenced these strategies with respect to a comprehensive analysis of the Chapel of Reconciliation.

\section{INFLUENCE ON DESIGN}

The analysis of precedent as a strategy of design process can serve several purposes, including the programmatic refinement of a project, the iteration of a relevant construction detail, learning practical lessons regarding costs or procurement, or the development of a formal language. In the fourth iteration of the assignment's delivery, a closer relationship was initiated between this exercise and the general theme of the studio projects of the third year, namely 'landscape' and 'memorial'. Figure 6 illustrates one of the clearest timeline examples becoming aligned and applied to studio design projects. This student's selection informed his development of funeral and memorial installations within a city park. There was an opportunity to select a building for the critical essay that would ultimately inform the design project: 'I was always aware the studio project would be on the forefront of everything I was to do this year meaning the Contemporary Influences module and the timeline would be used to advance my proposal. ${ }^{\prime 19}$

The timeline initially illustrated an inquiry into 'forms of remembrance' through the general evolution of memorials, incorporating the Pyramids, crematoria, and natural burial structures. The second phase was to select a set of precedents that embedded both the ideas of landscape and memorial. Once established, the two data sets were graphically compared in terms of a 'constructed sequence embodying memory', adopting a key architectural strategy concerning promenade / circulation. The last part of the timeline was to produce a conceptual diagram of the relationship between constructed elements and the natural landscape, representing 'the built form of memory meeting its place'. Analytical annotations and explanatory captions refined and strengthened the visual analysis.

This graphic analysis provided the structure of the student's subsequent critical essay, entitled 'Place sensitive architecture storing a memory about life: a journey through a memorial landscape.' The first part of the essay focused on 'contextualization' exploring the notions of collective memory as a thematic generator of memorial architecture, Norwegian architecture of remembrance, and the architectural promenade. This was followed by a critical evaluation of Zumthor's Zinc Mine Museum, focusing upon its relationship to the landscape applicable materiality, and the concept of 'unfortunate memory'.

On interrogating this student's development work for his studio project, emergent architectural strategies of a constructed sequence in approaching the building, combined with the concept of 'dots in the wilderness' have been implemented in the project's realization. Therefore, the student consequently employed this focused analysis of precedents (Figure 6) to critically inform his personal design process. 
LINES OF INQUIRY - Architectural strategies

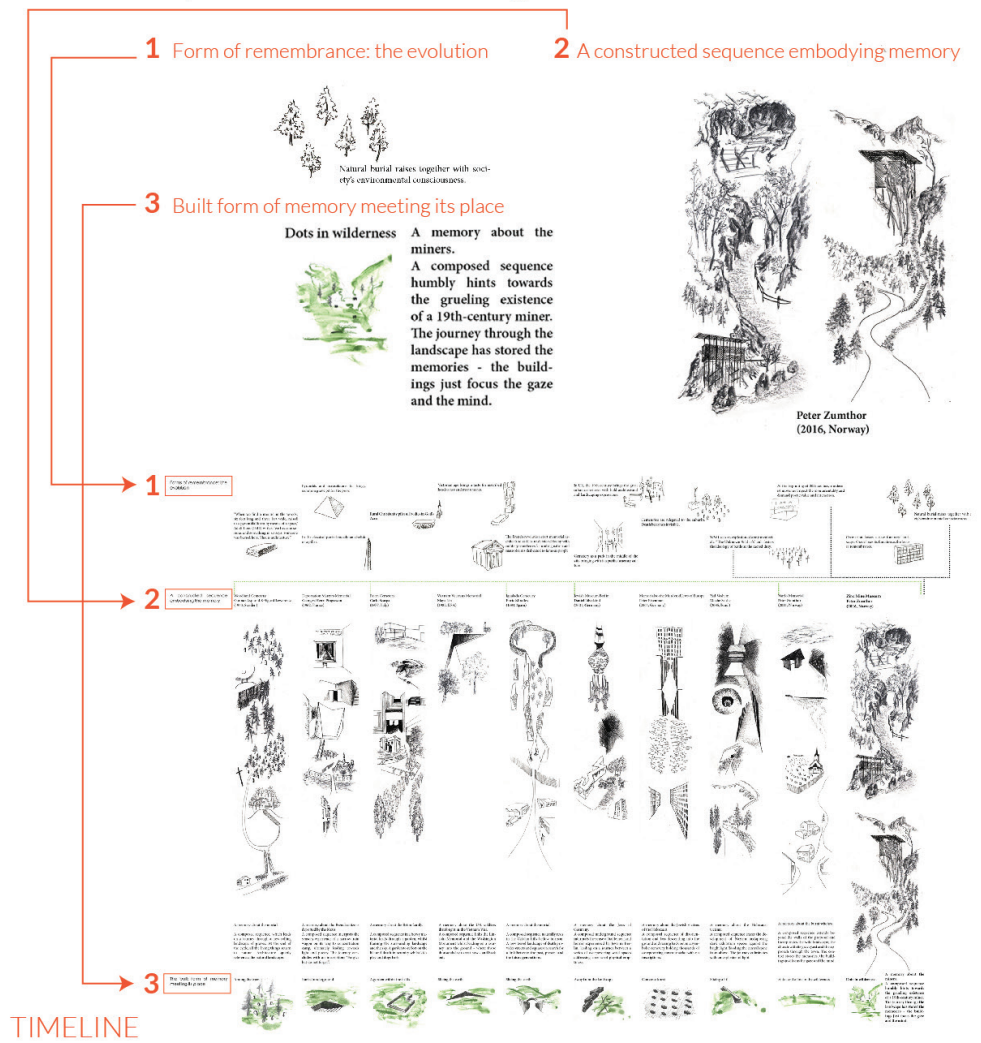

STUDIO PROJECT - Reading of the site

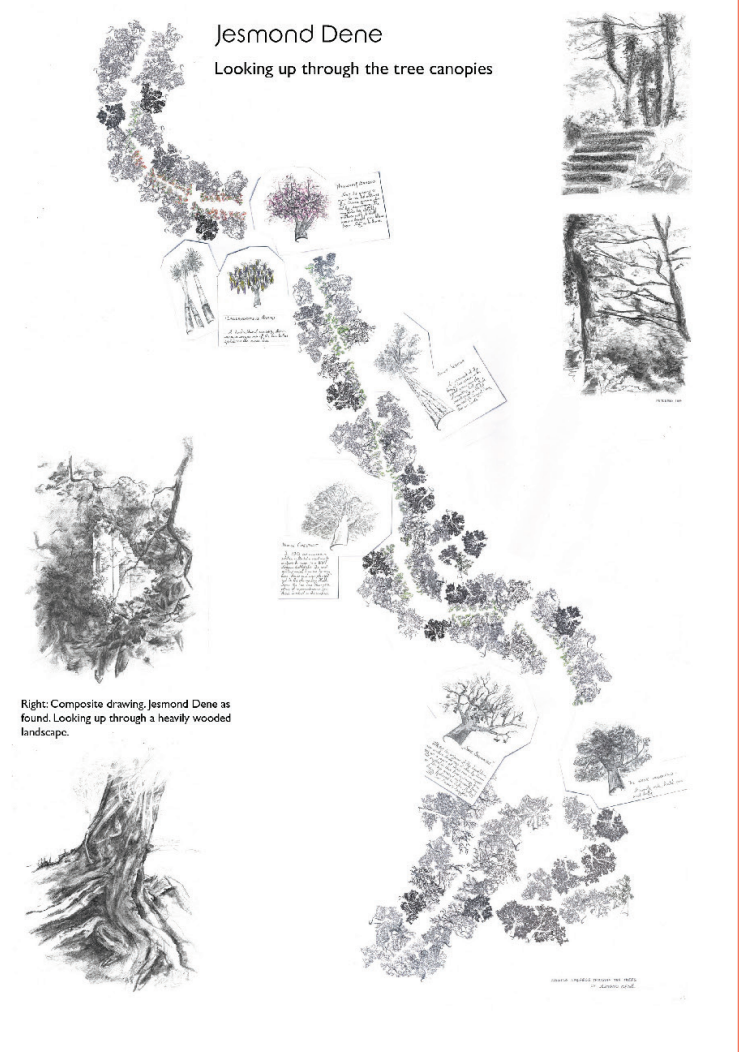

Figure 6. Ingmars Upatnieks's timeline for the Zinc Mine Museum (lower left), the lines of inquiries (upper left) and application of strategies to studio design project (right) - Academic Year 2018-19.

In analyzing the design development for the studio design project, there is a clear application of strategies derived from this assignment. For example, precedents are used to inform technical solutions and detailed resolution, site strategy (including the 'promenade), even the use of architectural communications methods that learn from the styles of key architects. Figure 7 clearly illustrates the influence of selected precedents on the design of the building section. Lessons from Zumthor's Zinc Mine Museum shape the student's design approach to how the building meets the ground. Furthermore, architectural strategies regarding the presentation of artworks emerges from Scarpa's drawings for Castevecchio, with the student developing a referential style of drawing ${ }^{20}$. Finally, the student's proposed carpentry similarly evokes the technical detailing of Thorncrown Chapel by E. Fay Jones.

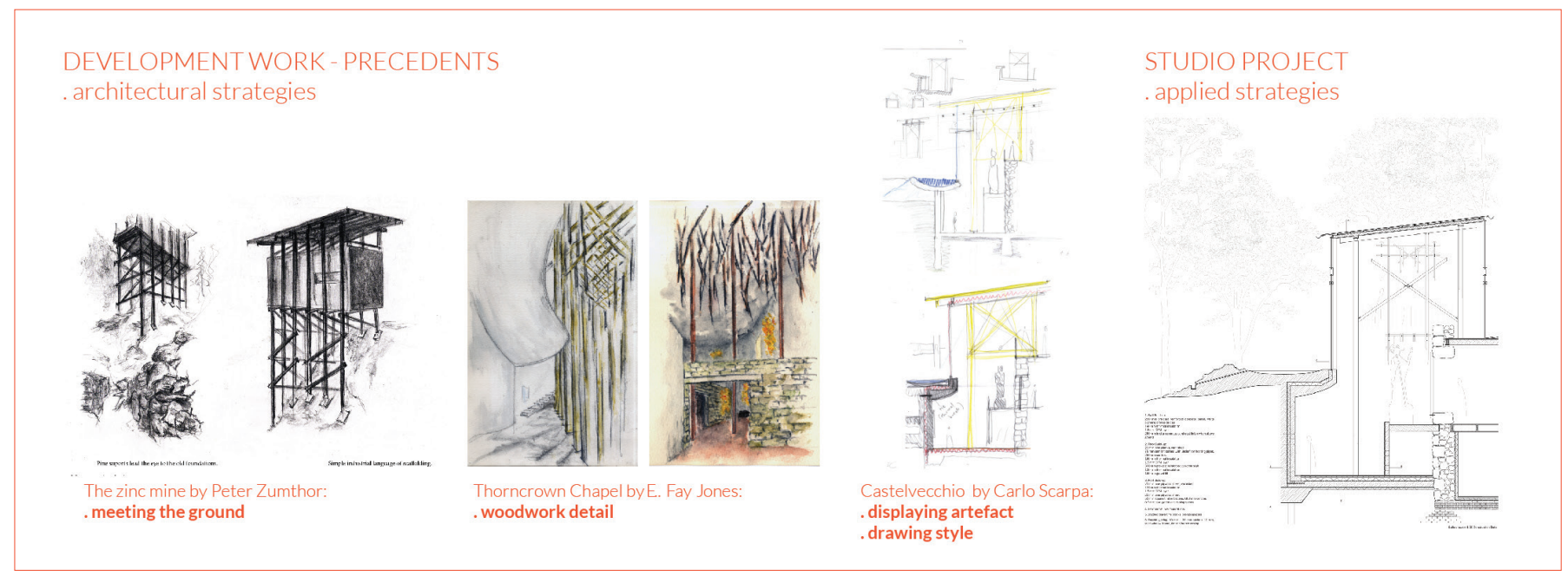

Figure 7. Ingmars Upatnieks's drawing studies based on selected precedents used for the design of the section for his studio project - Academic Year $2018-19$. 


\section{SUMMARY}

The timeline exercise has sought to employ the visual methodologies and communications skills inherent within architectural education as complementary tools of analysis that can support traditional academic writing in evidencing critical judgement on the part of the student. Over several iterations of its implementation, the timeline exercise has evolved from a visual alternative to writing into a tool that can analyze precedents towards the generation of architectural strategies, as well as strengthening critical thinking during the design process, resulting in evidence-based studio work. The critical comparison of architectural strategies across a set of interrelated buildings seeks to make students aware of alternatives, as well as to synthesize new approaches. The timeline has helped to recontextualise historical learning and theoretical concepts as practical applications that can inform and support high quality architectural design.

In seeking to guide students to go beyond superficial imagery, critical thinking is instilled towards precedent analysis that informs justified design decisions in studio projects. Students are encouraged to extend their scope of inquiry beyond formal considerations towards engagement with the wider contexts that influence architectural history and theory, as well as to develop comparative methods as a way of learning. Having developed their own personal critical framework, students are then able to reflect critically on their own work and the work of others, thereby to practically applying this learning to the design studio (Figure 8).

\section{Notes}

1. Amos Rapoport, History and Precedent in Environmental Design (Springer Science \& Business Media, 2013).

2. Based on the Directive 2005/36/EC of the European Parliament and of the Council of 7 September 2005 on the Recognition of Professional Qualifications, Chaper III, Section 8, Article 46, 'Training of Architects'. Available at: https://eur-lex.europa.eu/legal-content/EN/TXT/ $\mathrm{HTML} /$ ?uri=CELEX:32005L0036\&from=EN\#d1e2728-22-1 (Accessed: 12th June, 2019).

3. $\mathrm{NAAB}$ (National Architecture Accrediting Board), '2014 Conditions for Accreditation', (2014, USA). Available at:

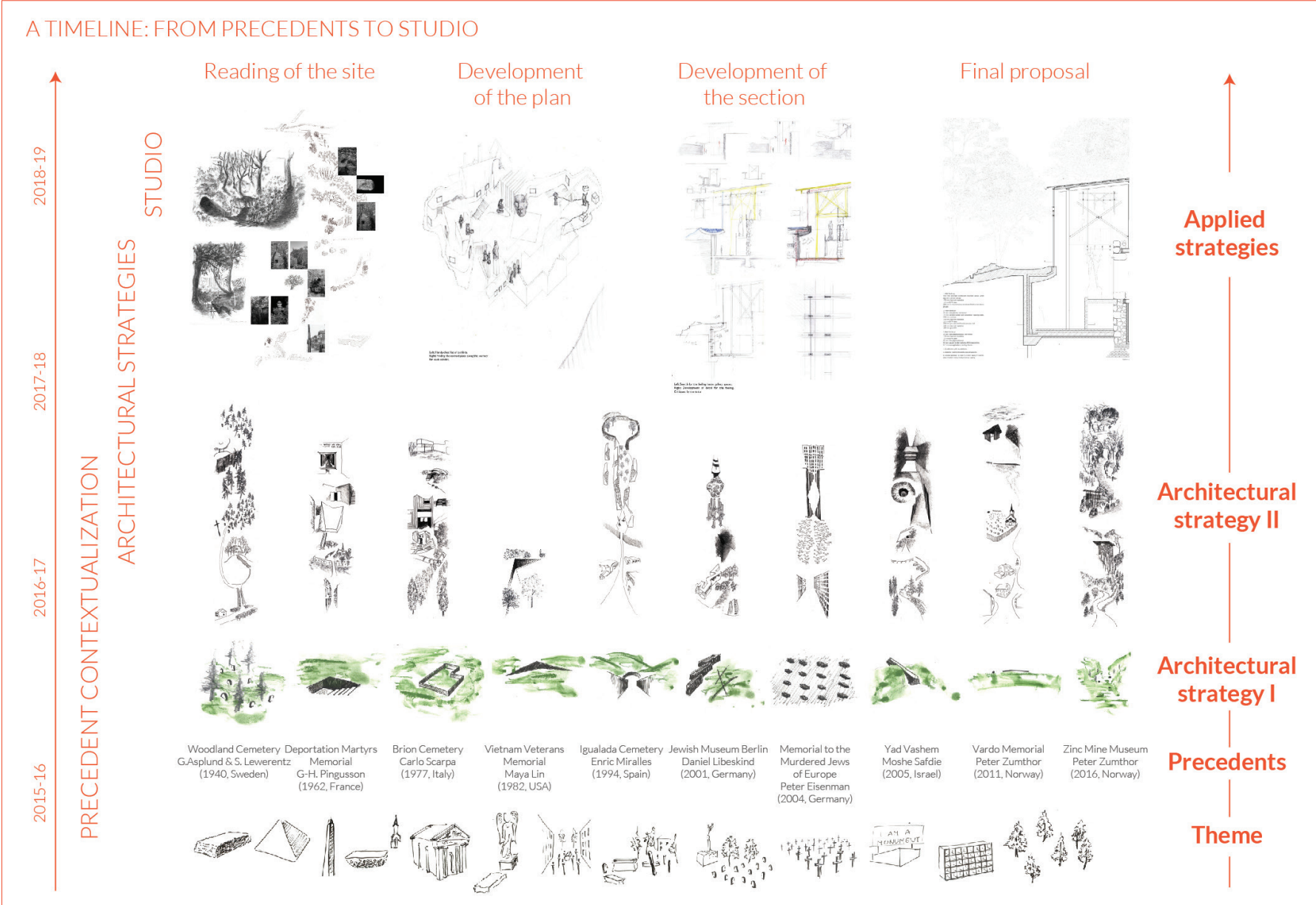

Figure 6. Ingmars Upatnieks's timeline for the Zinc Mine Museum (lower left), the lines of inquiries (upper left) and application of strategies to studio design project (right) - Academic Year 2018-19. 
https://www.naab.org/wp-content/uploads/01_Final-

Approved-2014-NAAB-Conditions-for-Accreditation-2.pdf (Accessed: 12th June, 2019).

4. $\quad$ ARB (Architects Registration Board), 'Prescription of Qualifications: ARB Criteria at Part 1, 2 and 3', (2012, UK). Available at: http://www.arb.org.uk/wp-content/ uploads/2017/11/ARB_Criteria.pdf (Accessed: 12th June, 2019).

5. Benjamin S. Bloom, Taxonomy of Educational Objectives. Vol. 1: Cognitive Domain (New York: McKay, 1956).

6. Dedre Gentner, Keith J. Holyoak and Boicho. N. Kokinov, The Analogical Mind: Perspectives from Cognitive Science (MIT press, 2001).

7. John E. Hancock, 'Between History and Tradition, Notes towards a Theory of Precedent'. Harvard Architecture Review, 5 (1986): 64-77.

8. Amanda R. Lawrence, 'Radical Acts of Influence: Thoughts on Anxiety, History, and the Culture of the Copy' Journal of Architectural Education, 69 (2015): 13-15.

9. Andrew Leach, What is Architectural History? (John Wiley \& Sons, 2013).

10 John B. Biggs, Teaching for Quality Learning at University: What the Student Does (McGraw-hill education, 2011).

11. Peter Holgate and Stephen Roberts, "Programming the Programme: Pacing the Curriculum in Architectural Education" (paper presented at the HEA STEM Conference, Imperial College London, 2012).

12. Erwin Panofsky and Benjamin Drechsel, Meaning in the Visual Arts (University of Chicago Press Chicago, 1955).

13. Michael Baxandall, Patterns of Intention: On the Historical Explanation of Pictures (Yale University Press, 1985).

14. Edward R. Tufte, The Visual Display of Quantitative Information (Graphics press Cheshire, CT, 2001).

15. Daniel Rosenberg and A.nthony Grafton, Cartographies of Time: A History of the Timeline (Princeton Architectural Press, 2013).

16. Charles Jencks, Architecture 2000: Predictions and Methods (Praeger, 1971).

17. Adrian Meyer, Susanne Kuhlbrodt and Beat Aeberhard, Architecture: a Synoptic Vision: Example of an Evolutionary History (Springer Verlag NY, 2008).

18. 'The timeline allowed me to develop a new research technique; I later adopted this research methodology as a way of filtering and understanding a complex topic.' Comment by George Bradford-Smith on the assignment (2th of July, 2019).

19. Comment by Ingmars Upatnieks on the assignment (19th of July, 2019).

20. The drawing style is inspired by Carlo Scarpa's drawing for the dispaly of the statue of Cangrande from Carlo Scarpa's digital archives (ref. 31583r/00057 - Statua di Cangrand Prospetto per il supporto a colonne della statua di Cangrand 